\title{
Preconcentration of Ferbam [Fe(III) tris(dimethyldithiocarbamate)] Using 1-(2-Pyridylazo)-2-naphthol Modified $\beta$-Cyclodextrin Polymer
}

\author{
SANDEEP JAGGI* and USHA GUPTA \\ Department of Chemistry, Punjabi University, Patiala-147002, India \\ jaggisandeep1987@gmail.com
}

Received 27 May 2014 / Accepted 24 June 2014

\begin{abstract}
In this study, $\beta$-Cyclodextrin polymer functionalized by 1-(2-pyridylazo)-2-naphthol (PAN) was synthesized and the resulting modified polymer was used for the preconcentration of $\mathrm{Fe}$ (III) tris(dimethyldithiocarbamate) by converting it into Fe(III)-PAN- $\beta$-CDP complex. For the described method, the effect of some analytical parameters, such as $\mathrm{pH}$, sample volume, contact time and volume of the eluent, on the recovery of Fe(III) tris(dimethyldithiocarbamate) were investigated. The recovery values were found to be $\geq 95 \%$. The developed method was utilized for the preconcentration and determination of Ferbam in different water samples.
\end{abstract}

Keywords: Ferbam, $\beta$-Cyclodextrin polymer, Functionalization, Preconcentration.

\section{Introduction}

Introduced 40-70 years ago, dithiocarbamate fungicides (DTCs) still represent an important class widely used in agriculture. They are characterized by a broad spectrum of activity against various plant pathogens, low acute mammal toxicity, and low production costs. They are also used to manage resistance and to broaden the spectrum of activity along with the modern systemic fungicides. DTCs are also used clinically for the treatment of chronic alcoholism and as anticancer and antitoxic drug agents ${ }^{1-4}$. Ferbam [Fe(III) tris $\{$ dimethyldithiocarbamate $\}],\left[\left\{\left(\mathrm{CH}_{3}\right)_{2} \mathrm{NCS}_{2}\right\}_{3} \mathrm{Fe}\right]$ is an agricultural dithiocarbamate fungicide used on a wide variety of plant fungi and diseases. It may be applied to the foliage of plants, but it is also used for soil or seed treatment. Ferbam is used primarily for almonds and stone fruits (drupes). There is a number of methods available in the literature for the determination of dithiocarbamates. One of such method explains about the determination of Ferbam by its decomposition into amine and carbon disulphide ${ }^{5}$. Ferbam is determined by converting it into molybdenum ${ }^{6}$ and copper $^{7}$ complexes. Dithiocarbamates have been determined using head space gas chromatography of the $\mathrm{CS}_{2}$ evolved under controlled conditions $^{8}$, high performance liquid chromatography ${ }^{9}$, extraction voltammetry $(\mathrm{EV})^{10}$. HGC and EV are time consuming, poor sensitive and suffer from interferences. Dithiocarbamates can also be determined by other methods such as iodometry ${ }^{11}, \operatorname{EDTA}^{12}$, polarography ${ }^{13}$, determination of the pesticides as their metallic components ${ }^{14-15}$, derivative spectrophotometry ${ }^{16}$, 
spectrophotometry $^{17}, H$-Point method $^{18}$, silica nanoparticles ${ }^{19}$, chitin $^{20}$, naphthalene ${ }^{21}$, flow injection spectrophotometry ${ }^{22}$. All of the above mentioned methods suffer from one or more disadvantages:

(a) Methods other than gas chromatography (GC) are indirect and time consuming, and their sensitivity is quite low.

(b) GC methods are sensitive but suffer from lack of selectivity because all dithiocarbamates pesticides evolve carbon disulphide on acid hydrolysis.

(c) HPLC methods are less sensitive than GC methods, they require a longer time for analysis and use of organic solvents as mobile phase and are relatively expensive.

$\beta$-Cyclodextrin $(\beta-C D)$ is a very stable oligosaccharide that is composed of seven glucose units linked with each other by $\alpha$ - $(1,4)$-glycosidic linkage. It can form supramoleculer complexes with several organic compounds by incorporating them into their hydrophobic cavities. When two or more $\beta$-Cyclodextrins are covalently linked with each other they are known as the polymers. These $\beta$-cyclodextrin polymers have been used for the preconcentration of various analytes ${ }^{23-26}$. Here, we have developed a relatively simple, rapid, sensitive and selective method for the determination of Ferbam by converting it into a $\mathrm{Fe}(\mathrm{III})-\mathrm{PAN}-\beta-\mathrm{CDP}$ complex. In AcOH-NaoAc buffer solution at $\mathrm{pH} 5.5$, Ferbam reacts with reagent loaded on $\beta$-CDP to form an earthy red colored complex. Chemical reaction between metal part of Ferbam with PAN to form coloured complex has been reported which is the base for their determination.

Fe-[tris(dimethyldithiocarbamate $)]+$ PAN $=$ Fe-PAN $+[$ tris(dimethyldithiocarbamate $)]$

\section{Experimental}

All reagents used were of analytical reagent grade. Double distilled water was used throughout the experiment. Ferbam was prepared as given in literature ${ }^{27}$. Its stock solution was prepared in dimethyl sulphoxide (DMSO). Further dilutions were made as and when required. $4 \times 10^{-6} \mathrm{~mol} / \mathrm{L}$ solution of the PAN reagent was prepared by dissolving an appropriate amount of PAN (Fluka Chemical Company) in $N, N$-dimethylformamide solvent. 1,4-Butanediol diglycidyl ether was obtained from sigma Aldrich chemical company (U.S.A.). $\beta$-Cyclodextrin was obtained from SD fine chemical India private limited (Mumbai). Buffer solution used were hydrochloric acid/ sodium acetate for $\mathrm{pH}$ 2.0-3.5, sodium acetate/acetic acid for $\mathrm{pH}$ 4.0-6.5, ammonia/ammonium chloride for $\mathrm{pH} 8-11$. Glassware were washed with chromic acid and soaked in 5\% nitric acid and rinsed with double distilled water. A Shimadzu UV-1800 spectrophotometer (Shimadzu Ltd., Japan) equipped with the matched $10-\mathrm{mm}$ quartz cells was used to measure absorbance. All $\mathrm{pH}$ measurements were performed using Digital century pH-meter CP 901 with a combined glass electrode. A thermostatic shaking water bath (Perfit India Ltd.) was used to carry out all the inclusive procedures.

\section{Procedure}

Synthesis of the $\beta$-Cyclodextrin polymer $(\beta-C D P)$

$\beta$-CDP was synthesized by known method ${ }^{28}$. A brief procedure for the synthesis is mentioned here. $20 \mathrm{~g}$ of $\beta-\mathrm{CD}$ was dissolved in $50 \mathrm{~mL}$ of $20 \% \mathrm{NaOH}$. To this $20 \mathrm{~mL}$ of butanediol diglycidyl ether was added drop wise. The polymer was formed in $1.5 \mathrm{~h}$ and dried at $90{ }^{\circ} \mathrm{C}$. The polymer was ground, sieved and washed with double distilled water 5-6 times. Then, the polymer was dried again at $90^{\circ} \mathrm{C}$ and kept at room temperature $\left(25^{\circ} \mathrm{C}\right)$ in a dessicator. 


\section{Inclusion of the PAN in the $\beta$-CDP cavity to form $\beta-C D P-P A N$ modified polymer}

$5.0 \mathrm{~g}$ of the synthesized polymer, $\beta$-CDP was taken in a $250 \mathrm{~mL}$ stoppered conical flask. To this $10 \mathrm{~mL}$ of $9.5 \mathrm{pH}$ buffer solution was added and polymer was allowed to swell for 15 minutes. A fixed volume of $4 \times 10^{-6} \mathrm{~mol} / \mathrm{L}$ solution of the PAN was added to the treated polymer and made $50 \mathrm{~mL}$ with distilled water. It was shaken for two hours. The colored polymer so obtained was washed with distilled water and dried at $100{ }^{\circ} \mathrm{C}$. The modified polymer was stored in a dessicator at room temperature for future use.

\section{Batch extraction procedure}

At room temperature i.e., $30{ }^{\circ} \mathrm{C} \beta$-CDP-PAN $(500 \mathrm{mg}$ ) and $10.0 \mathrm{~mL}$ of buffer solution (pH 9.5) were added to a $100 \mathrm{~mL}$ stoppered conical flask. The mixture was allowed to stand for approximately $15 \mathrm{~min}$ so that $\beta$-CDP-PAN could be swollen sufficiently. $75 \mu \mathrm{g}$ of Ferbam were added and made up to $100 \mathrm{~mL}$ with double distilled water. After the mixture was shaken in the thermostatic shaking water bath for $45 \mathrm{~min}, 5.0 \mathrm{~mL}$ of the supernatant solution was transferred into a $10 \mathrm{~mL}$ volumetric flask and the absorbance was measured using standard spectrophotometric method $^{29}$. Ferbam retained on $\beta$-CDP-PAN polymer was eluted using $5.0 \mathrm{~mL}$ of $2 \mathrm{M} \mathrm{HCl}$.

\section{Sample collection and conditioning}

Water samples were collected from the different parts of Patiala City, India. The water samples were immediately filtered through cellulose membrane filter $(0.45 \mathrm{~nm}$ pore size $)$, and stored in pre-cleaned polyethylene bottles. After then, $\mathrm{pH}$ of the sample was adjusted to 5.5 and the preconcentration procedure as described above was applied

\section{Results and Discussion}

\section{Effect of $p H$}

The sorption of an analyte on the chelating resin is dependent on the $\mathrm{pH}$ of sample solution due to the competitive reaction between chelate forming groups and hydrogen ions in the solutions $^{30} .75 \mu \mathrm{g}$ of Ferbam were spiked to a $100 \mathrm{~mL}$ of the model solution. The $\mathrm{pH}$ of this solution was adjusted in the range of 2.5 to 10.5 using different buffer solutions and then the preconcentration procedure as described was applied. As it can be seen in Figure 1, quantitative uptake ( $\geq 95 \%$ ) was obtained at $\mathrm{pH} 5.5$. Therefore, the working $\mathrm{pH}$ was chosen as 5.5 for the following experiments.

\section{Effect of shaking time}

Shaking time is an important factor in determining the possibility of application of the $\beta$ CDBP-PAN polymer for the selective uptake of Ferbam. Different shaking time (ranging from 15 to $75 \mathrm{~min}$ ) were studied for the $\%$ uptake of Ferbam by $\beta$-CDP-PAN polymer. The results of \% uptake of Ferbam vs. the shaking time show that the percentage uptake reach maximum (above 95\%) at $45 \mathrm{~min}$ (Figure 2). Therefore, the shaking time of $45 \mathrm{~min}$. was selected as the adsorption equilibrium time.

\section{Effect of the sample volume}

In order to explore the possibility of enriching low concentration of analytes from large volume of solution, the effect of sample volume on the retention of Ferbam was also investigated. For this purpose, 25, 50, 100, 150, 200, 250, 300, 350 and $400 \mathrm{~mL}$ of sample solutions containing $75 \mu \mathrm{g}$ of Ferbam were taken. Quantitative uptakes $(\geq 95 \%)$ were obtained for sample volume of $\leq 300 \mathrm{~mL}$ (Figure 3). Therefore, $100 \mathrm{~mL}$ of sample solution was adopted for the preconcentration of analyte from sample solutions. 


\section{Effect of elution conditions on recovery}

Since the adsorption of Ferbam at $\mathrm{pH} \leq 2$ is quite low, one can expect that elution will be favored in the acidic solutions. So various concentrations and volumes $\mathrm{HCl}$ were used for the desorption of retained Ferbam. The experimental results showed that $2 \mathrm{M} \mathrm{HCl}$ was sufficient for complete elution of Ferbam. It was found that quantitative recoveries $(\geq 95 \%)$ with $4.0 \mathrm{~mL}$ of $2.0 \mathrm{M} \mathrm{HCl}$ as eluent could be obtained (Figure 4). Therefore, for eluting Ferbam $4.0 \mathrm{~mL}$ of $2.0 \mathrm{M} \mathrm{HCl}$ was used as eluent.

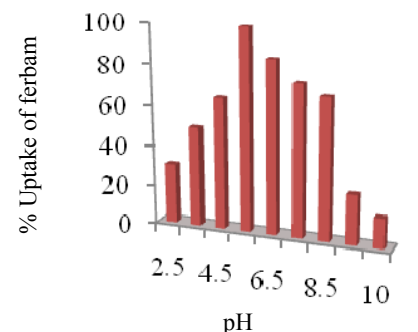

Figure 1. Effect of $\mathrm{pH}$ on the \% uptake of Ferbam

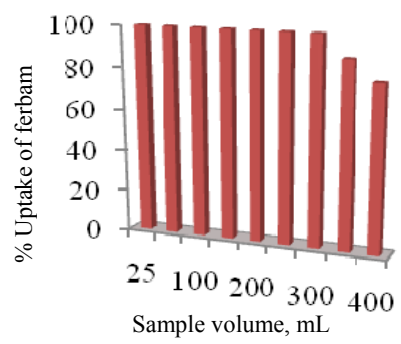

Figure 3. Effect of the sample volume on the $\%$ uptake of Ferbam

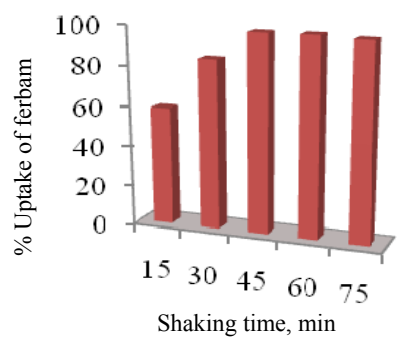

Figure 2. Effect of the contact time on the $\%$ uptake of Ferbam.

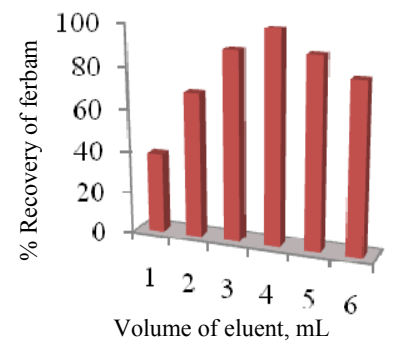

Figure 4. Effect of eluent volume on \% uptake of Ferbam

\section{Applications of the method}

The method was applied to the determination of Ferbam in different water samples. The results are given in the Table 1. The accuracy of the described preconcentration method was tested in the recovery studies by adding known amounts of Ferbam to the water sample. The recovery values obtained from the water samples were satisfactory. These results confirm the validity of the proposed method.

Table 1. Determination of Ferbam in different water samples, $(n=3)$

\begin{tabular}{ccccc}
\hline Sample & Spiked, $\mu$ g. & Found, $\mu$ g. & $\begin{array}{c}\% \text { Relative } \\
\text { Error }\end{array}$ & $\begin{array}{c}\% \text { Recovery } \\
\pm \text { R.S.D., } \%\end{array}$ \\
\hline \multirow{3}{*}{ Tap Water } & 0.0 & N.D & - & - \\
& 15.0 & 14.7 & 2.9 & $9.7 .1+2.1$ \\
& 20.0 & 19.5 & 2.5 & $97.5+1.5$ \\
Bore Water & 0.0 & N. D. & - & - \\
& 35.0 & 34.0 & 1.0 & $99.0+1.0$ \\
& 40.0 & 38.7 & 1.7 & $98.3+1.2$ \\
River Water & 0.0 & N.D & - & - \\
& 55.0 & 54.6 & 1.0 & $99.0+1.0$ \\
& 65.0 & 64.4 & 1.0 & $99.1+1.0$ \\
\hline
\end{tabular}




\section{Conclusion}

The proposed preconcentration method consists of a simple and low cost procedure which permits the quantitative recovery of Ferbam from water and vegetable samples. Owing to the synthesized chelating polymer having high affinity for Ferbam, its selective determination is possible. The chelating polymer has been used along all the experiments performed for this study. Because of that it has superior reusability. The recovery values were found to be $\geq 95 \%$. The method has an enrichment factor of 75 .

\section{References}

1. Chen D, Qiuzhi Cindy Cui, Huanjie Yang and Q. Ping Dou, Cancer Res., 2006, 66(21), 10425-10433; DOI:10.1158/0008-5472.CAN-06-2126

2. Viola-Rhenals M, Rieber M S and Rieber M, Biochem Pharmacol., 2006, 71(6), 722-734; DOI:10.1016/j.bcp.2005.11.028

3. Frank N, Christmann A and Frei E, Toxocology, 1995, 95(1-3), 113-112; DOI:10.1016/0300-483X(94)02890-7

4. Vettorazzi G, Almeida W F, Burin G J, Jaeger R B, Puga F R, Rahde A F, Reyes F G, Schvartsman S et al., Teratog Carcinog Mutagen., 1995, 15(6), 313-337.

5. Clarke D, Harry Baum, Stanley E and Hester W, Anal Chem., 1951, 23(12), 1842 1846; http://dx.doi.org/10.1021/ac60060a034

6. Rao A L J and Verma N, J Indian Acad Forensic Sci., 1985, 24, 1.

7. Rangaswamy J R, Poornima P and Majumdar S K, J Assoc Off Anal Chem., 1970, 53, 1043.

8. McLeod H A and McCulley K A, J Assoc Off Anal Chem., 1969, 52, 1226.

9. Gustafsson K H and Falhgren C H, J Agric Food Chem., 1983, 31(2), 461-463; DOI:10.1021/jf00116a074

10. Valkanovich N A, Medyantseva E D, Frolova V F and Romanova O N, Zh Anal Khim., 1983, 38, 1963.

11. Clyde D D, J Assoc Off Anal Chem., 1983, 66, 646.

12. Hyman A S, Analyst, 1969, 94, 152-153; DOI:10.1039/AN9699400152

13. Halls D J, Townshend A and Zumen P, Analyst, 1968, 93, 219-223; DOI:10.1039/AN9689300219

14. Quintero M C, Silva M and Perez-Bendito D, Talanta, 1991, 38(4), 359-363; DOI:10.1016/0039-9140(91)80072-8

15. Perez-Ruiz T, Carmen Martinez-Lozano, Virginia Tomás and Rocio Casajús, Talanta, 1996, 43(2), 193-198; DOI:10.1016/0039-9140(95)01714-3

16. Malik A K, Bansal S and Aulakh J S, Anal Bioanal Chem., 2002, 375, 1618.

17. Zaijun L, Fan You, Liu Zhongyun and Tang Jian, Talanta, 2004, 63(3), 647-651; DOI:10.1016/j.talanta.2003.12.007

18. Kaur P P and Gupta U, J Chem., 2009, 6(1), 106-112; DOI:10.1155/2009/514251

19. Kaur A and Gupta U, Eurasian J Anal Chem., 2011, 6(1), 1-12.

20. Mehta S K, Malik A K, Singh B and Rao A L J, Talanta, 2005, 67(4), 725-729; DOI:10.1016/j.talanta.2005.03.022

21. Malik A K, Sharma V, Sharma V K and Rao A L J, J Agric Food Chem., 2004, 52(26), 7763-7767; DOI:10.1021/jf040326h

22. Perez-Ruiz T, Carmen Martínez-Lozano, Virginia Tomás, Antonio Sanz and Raquel Garre, Microchim Acta, 2003, 142(4), 231-235; DOI:10.1007/s00604-003-0027-z

23. Abay I, Denizli A, Biskin E and Salih B, Chemosphere, 2005, 61(9), 1263-1272; DOI:10.1016/j.chemosphere.2005.03.079 
24. Shao D, Sheng G, Chen C, Wang X and Nagastu M, Chemosphere, 2010, 79(7), 679685; DOI:10.1016/j.chemosphere.2010.03.008

25. Wu M and Zhu X, Spectrochim Acta A Mol Biomol Spectrosc., 2010, 77(5), 10211024; DOI:10.1016/j.saa.2010.08.061

26. Bhaskar M, Aruna P, Rama Jeevan Ganesh Jeevan and Radhakrishnan G, Anal Chim Acta, 2004, 509(1), 39-45; DOI:10.1016/j.aca.2003.12.015

27. Kapoor J and Rao A L J, Pestic Sci., 1994, 42(2), 109-112; DOI:10.1002/ps.2780420207

28. Komiyama M and Hirai H, Polym J., 1987, 19(6), 773-775.

29. Snell F T and Snell C T, Colorimetric Methods of Analysis $3^{\text {rd }}$ Edn., Van Nostrand: New York.

30. Minami T, Atsumi K and Ueda J, Anal Sci., 2003, 19(2), 313-315. 